ASIMTOT: JURNAL KEPENDIDIKAN MATEMATIKA

Volume 1 Nomor 1, Januari - Mei 2019, halaman 61 - 67

Tersedia Daring pada https://journal.unwira.ac.id/index.php/Asimtot

\title{
PENGARUH MODEL PEMBELAJARAN TUTOR SEBAYA TERHADAP PRESTASI BELAJAR MATEMATIKA SISWA
}

\section{THE EFFECT MODELS OF PEOPLE'S TUTOR LEARNING ON MATHEMATICS LEARNING ACHIEVEMENT OF STUDENTS}

\author{
Petrus Abineneo, Yohana Rina Rowa, Yohanes Ovaritus Jagom \\ Universitas Katolik Widya Mandira \\ Hlesiangi@gmail.com, yohanarowa@gmail.com, kraengyovanmgr@gmail.com
}

\begin{abstract}
Abstrak: Masalah pokok dalam penelitian ini yaitu bagaimana pelaksanaan model pembelajaran dan pengaruh terhadap prestasi belajar matematika siswa pada sub pokok bahasan faktorisasi suku aljabar di SMP Negeri 20 Kota Kupang tahun ajaran 2017/2018. Tujuan dari penelitian ini yaitu untuk mengetahui pelaksanaan pembelajaran dan pengaruh model pembelajaran tutor sebaya terhadap prestasi belajar matematika siswa pada sub pokok bahasan faktorisasi suku aljabar di SMP Negeri 20 Kota Kupang tahun ajaran 2017 / 2018. Penelitian ini dilakukan pada siswa kelas VII SMP Negeri 20 Kota Kupang yang berjumlah 30 orang siswa dan dipilih secara acak dari 5 kelas yang tersedia. Instrumen yang digunakan dalam penelitian ini yaitu observasi, wawancara, dan tes prestasi belajar matematika siswa sebayak 30 butir soal berbentuk pilihan ganda. Teknik analisis data yang digunakan dalam penelitian ini yaitu hasil observasi, hasil wawancara, pencapaian indikator dan uji-t. Berdasarkan hasil observasi, hasil wawancara, dan pencapaian indikator, diperoleh prestasi belajar matematika siswa tergolong sangat baik. Sedangkan berdasarkan perhitungan uji-t menunjukkan $\mathrm{t}$ hitung $=$ 16,417 dan $\mathrm{t}$ table $=2,045$ pada taraf signifikani $5 \%$ yang berarti $\mathrm{t}$ hitung $>\mathrm{t}$ tabel , Maka Ho ditolak dan Ha diterima. Sehingga dapat diambil kesimpulan bahwa ada pengaruh yang signifikan pada pengunaan model pembelajaran tutor sebaya
\end{abstract}

Kata Kunci: Model Pembelajaran Tutor Sebaya , Prestasi Belajar.

Abstract: This Main problem in this research that is about how execution of study model of tutor coeval on sub subjek of rectangular in SMP Negeri 20 Kupang city academic year 2017 /2018. The purpose this research is to know implementation of learning and the effect of learning model tutor coeval to achievement learn mathematics student's on sub subjek of rectangular in SMP Negeri 20 Kupang city academic year 2017 / 2018.This research was conducted on VII grade student's SMP Negeri 20 Kupang city which amounted to 30 students selected randomly from 5 classes available.The instrument used in thes research are observation, interview and achievement tes learn much as 30 problem item in from of double helix.Data analysis technique used in this research that is result of observation .result of interview, achievement of indicator and $t$-test. Based on the results of observation, result of interview, achievement of indicators, obtained achievement learn mathematics student are very good. While based on $t$-test calculation shows $t$ count $=16,417$ and the table $=2,045$ at significance level $5 \%$ which means $t$ count $>t$ table, then Ho rejected Ha accepted. So it can be concluded that there is a significant influence on the use learnig model of tutor coeval.

Keywords: Learning model study tutor coeval, learning achievement.

Cara Sitasi: Petrus, A., Yohana,R.,R \& Yohanes, O.J, (2019). Pengaruh Model Pembelajaran Tutor Sebaya Terhadap Prestasi Belajar matematika Siswa. Asimtot: Jurnal Kependidikan Matematika, 1(1), 61 - 67 
Dalam Kamus Besar Bahasa Indonesia disebutkan bahwa pendidikan adalah: "Proses perubahan sikap dan tingkah laku seseorang atau kelompok orang dalam usaha mendewasakan manusia melalui upaya pengajaran dan pelatihan". Guru memiliki peranan penting dalam pendidikan disekolah, dalam menerapkan pembelajaran sampai siswa menguasai materi pelajaran secara tuntas. Pembelajaran yang berhasil ditunjukan bukan hanya saat dikuasainya materi pelajaran yang diajarkan saja melainkan siswa juga dapat mempergunakan ilmu pengetahuan yang mereka punya dan mengaplikasikan di masyarakat.

Prestasi belajar adalah kemampuan yang diperoleh anak setelah melalui kegiatan belajar. Karena belajar itu sendiri merupakan suatu proses dari seseorang yang berusaha untuk memperoleh suatu bentuk perubahan perilaku yang relative menetap. Untuk mengetahui apakah prestasi belajar yang dicapai telah sesuai dengan tujuan yang dikehendaki dapat diketahui melalui evaluasi. Dari evaluasi tersebut terdapat anak yang masih belum mencapai ketuntasan belajar. Dilihat masih ada anak yang mengalami kesulitan belajar sehingga guru perluh mencari cara yang dapat membantu siswa tersebut untuk memenuhi ketuntasan belajarnya.

Ketuntasan belajar yakni pencapaian taraf penguasaan minimal yang ditetapkan secara perorangan. Selain itu kita semua tahu bahwa kemampuan setiap siswa berbeda-beda dalam kecepatan menerima pelajaran ada siswa yang cepat,sedang dan rendah. Sebelum pengajaran diberikan guru terlebih dahulu melihat kesulitan belajar yaitu menentukan jenis dan penyebab kesulitan serta alternatife model pembelajaran yang efektif dan efisien.

Salah satu penyebab kesulitan belajar siswa itu dapat dilihat dari salah satu kondisi siswa yang masih bingung dalam pemfaktoran bentuk aljabar, masih sering terjadi kekeliruan dalam pengerjaan soal-soal. Materi ini bukan hanya menuntut siswa untuk paham cara pemfaktoran suatu bilangan,tetapi juga paham dari perkalian. Ada siswa yang cepat mengerti dengan materi yang diajarkan dan ada juga siswa yang lambat. Bagi siswa yang cepat paham dengan materi yang diajarkan bisa mengajari teman-temannya, menjadi sumber belajar atau fasilitator dalam belajar yang baik. Dalam mengatasi masalah tersebut peneliti mencoba menggunakan model pembelajaran Tutor Sebaya dalam materi faktorisasi suku aljabar yang lebih menuntut siswa untuk berperan aktif dalam proses pembelajaran baik itu secara individual ataupun keseluruhan.

Dalam model pembelajaran Tutor Sebaya siswa tidak hanya aktif dalam proses pembelajaran saja tetapi juga dapat membangun hubungan yang lebih akrab antara siswa yang dibantu dan bagi Tutor itu sendiri. Kegiatan pengajaran ini merupakan kesempatan untuk pengayaan dalam belajar dan juga dapat menambah motivasi belajar serta dapat meningkatkan rasa tanggung jawab dan percaya diri.

Berdasarkan pengalaman, peneliti melakukan kegiatan PPL ditemukan beberapa permasalahan diantaranya, rendahnya prestasi belajar siswa, kurangnya pengetahuan tentang materi yang diajarkan dan lemahnya penghafalan rumus perkalian serta kekeliruan dalam pengerjaan soal sehingga terjadi kesulitan dalam mengaplikasikan rumus pada 
penyelesaian soal latihan. Hal ini dapat dilihat dari nilai yang didapatkan siswa yang belum mencapai kriteria ketuntasan minimal KKM.

Sebelum menerapkan model pembelajaran Tutor Sebaya, Guru harus menentukan siswa-siswa yang sudah mencapai ketuntasan belajar dan siswa -siswa yang belum mencapai ketuntasan belajar. Guru juga harus mempersiapkan Tutor-Tutor agar pelajaran berjalan optimal, karena tidak semua siswa yang sudah mencapai ketuntasan bisa menjadi tutor yang baik. Dalam penentuan pasangan Tutor harus dipertimbangkan kecocokan dan kenyamanan pada masing -masing kelompok.

Dari permasalahan yang telah diuraikan tersebut peneliti bermaksud untuk melakukan suatu penelitian dengan judul ' Pengaruh model pembelajaran Tutor Sebaya terhadap prestasi belajar matematika siswa SMPN 20 Kupang. Tujuan penelitian ini adalah untuk mendeskripsikan model pembelajaran Tutor Sebaya pada siswa ,mendeskripsikan prestasi belajar matematika siswa dan mengetahui pengaruh model pembelajaran Tutor Sebaya terhadap prestasi belajar matematika siswa.

Menurut Joice \& Weil (Isjoni, 2013) model pembelajaran adalah suatu pola atau rencana yang sudah direncanakan sedemikian rupa dan digunakan untuk mengatur materi pelajaran, dan memberi petunjuk kepada pengajar di kelasnya. Usaha guru dalam membelajarkan siswa merupakan bagian yang sangat penting dalam mencapai keberhasilan tujuan pembelajaran yang sudah direncanakan. Menurut Ngalimun (2012) Model Pembelajaran adalah suatu rancangan atau pola yang digunakan sebagai pedoman pembelajaran di kelas. Artinya model pembelajaran adalah suatu rancangan yang digunakan guru untuk melakukan pengajaran di kelas.

Berdasarkan uraian di atas dapat disimpulkan bahwa model pembelajaran adalah rancangan dan pola yang digunakan sebagai pedoman dalam proses pembelajaran yang berkaitan dengan pengetahuan, sikap ataupun keterampilan demi tercapainya suatu tujuan pembelajaran.

Menurut Djamarah (2010) model pembelajaran Tutor Sebaya sangat tepat untuk mendapatkan anak didik secara keseluruan dan individual.Model pembelajaran ini memberi kesempatan kepada setiap anak didik untuk berperan sebagai guru bagi teman-temannya.Dengan model pembelajaran ini anak didik yang selama ini tidak mau terlibat akan ikut serta dalam pembelajaran secara aktif.

Adapun langkah-langkah tersebut adalah:

a.) Menentukan siswa yang akan dijadikan Tutor.

Menurut Satryaningsi (2009) dalam menentukan siapa yang akan dijadikan Tutor diperluhkan pertimbangan-pertimbangan tersendiri. Seorang Tutor yang dipilih harus memiliki kriteria-kriteria sebagai berikut:

1.) Memiliki kepandaian lebih unggul dari pada siswa lain.

2.) Memiliki kecakapan dalam menerima pelajaran yang disampaikan oleh guru.

3.) Mempunyai kesadaran untuk membantu teman lain.

4.) Mampu menjalin kerja sama dengan sesama siswa. 
5.) Memiliki motivasi tinggi untuk menjadikan semua kelompok sebagai yang terbaik.

6.) Dapat diterima dan disenangi siswa sehingga siswa tidak mempunyai rasa takut atau enggan untuk bertanya kepadanya dan rajin.

7.) Tidak tinggi hati,kejam atau keras hati terhadap sesama teman.

8.) Mempunyai daya kreatifitas yang cukup untuk memberikan bimbingan yaitu dapat menerangkan pelajaran kepada temannya.

b.) Menyiapkan Tutor

Menurut Suparno(2007) ada beberapa cara yang perluh diperhatikan dalam menyiapkan seorang Tutor agar Tutor dapat bekerja secara optimal. Cara tersebut yaitu:

1.) Guru memberikan petunjuk pada Tutor bagaimana mendekati temannya dalam hal memahami materi.

2.) Guru menyampaikan pesan kepada Tutor-Tutor agar tidak selalu membimbing teman yang sama.

3.) Guru membantu agar setiap siswa dapat menjadi Tutor sehingga mereka merasa dapat membantu teman belajar.

4.) Guru memonitoring kapan Tutor maupun siswa lain membutuhkan pertolongan.

5.) Guru memonitoring Tutor dengan berkunjung dan menanyakan kesulitan yang dihadapi setiap kelompok pada saat mereka diskusi.

c.) Membagi kelompok

Dalam model pembelajaran Tutor Sebaya,Seorang guru bertindak sebagai pengawas dan pengatur jalanya pembelajaran dikelas. Sebelum memulai menerapkan model pembelajaran Tutor Sebaya, seorang guru harus membagi peserta menjadi kelompokkelompok kecil. Mengenai berapa banyaknya anggota setiap kelompok tidak ada ketentuan yang mutlak harus ditaati sebagai pedoman. Kelompok kecil sebaiknya dengan anggota 45 orang. Dengan dasar pemikiran bahwa makin banyak anggota kelompoknya, keefektifan belajar tiap anggota kelompok berkurang. Sebaliknya jika terlalu sedikit 2 atau 3 orang kurang dapat membentuk iklim kelompok yang baik.

Kelompok-kelompok dalam model pembelajaran Tutor Sebaya ini dapat dibentuk atas dasar minat dan latar belakang,pengalaman atau prestasi belajar. Maka langkah- langkah model pembelajaran Tutor Sebaya adalah:

1.) Membagi siswa menjadi beberapa kelompok yang terdiri dari 4-5 orang. Pada masing-masing kelompok terdapat seorang siswa ditunjuk oleh peneliti sebagai Tutor (Pemilihan Tutor akan dipilih berdasarkan informasi yang di dapatkan peneliti dari guru mata pelajaran matematika).

2.) Guru menyampaikan sekilas informasi tentang materi faktorisasi aljabar.

3.) Guru memberikan LKS yang berisi tentang soal-soal yang berhubugan dengan materi faktorisasi suku aljaba

4.) Masing masing kelompok mendapat LKS dan mendengarkan penjelasan guru serta bertanya jika ada yang perluh ditanyakan tentang cara kerja LKS tersebut.

5.) Masing-masing Tutor mengkoordinir proses diskusi agar berlangsung dengan baik.

6.) Guru mengawasi kegiatan belajar siswa selama diskusi berlangsung dan membantu siswa jika ada yang mengalami kesulitan dalam menyelesaikan soal-soal yang terdapat dalam LKS. 
7.) Guru memanggil siswa dari setiap kelompok secara acak untuk menjawab di depan kelas.

8.) Guru memberikan penghargaan pada kelompok individu yang menjawab benar.

9.) Guru membimbing siswa membuat kesimpulan tentang materi yang telah dibahas.

10.) Guru memberikan tes akhir (posttest) kepada seluruh siswa.

Kata"prestasi"berasal dari bahasa belanda yaitu prestatie. Kemudian dalam bahasa Indonesia menjadi "prestasi" yang berarti "hasil usaha".Istilah prestasi belajar (Achievement) berbeda dengan hasil belajar (Learning outcome). Menurut Dimyati dan Mujiono(2009:200) Mengemukakan bahwa prestasi belajar merupakan tingkat keberhasilan yang dicapai oleh siswa setelah mengikuti suatu kegiatan pembelajaran,dimana tingkat keberhasilan tersebut ditandai dengan skala nilai berupa huruf atau kata atau symbol.

Prestasi belajar adalah tingkat keberhasilan peserta didik mencapai tujuan yang telah ditetapkan dalam sebuah program (Muhibbin Syah 2010:139). Lebih lanjut lagi, muhibbin Syah menjelaskan alat ukur yang banyak digunakan untuk menentukan tingkat keberhasilan proses belajar mengajar adalah assesment yang lebih dikenal dengan tes,ujian ulangan.

Berdasarkan uraian tersebut,dapat disimpulkan bahwa prestasi belajar adalah tingkat keberhasilan siswa mencapai tujuan yang telah ditetapkan dalam proses belajar yang dapat diketahui melalui tes ujian ulangan dalam bentuk nilai.Peserta didik yang nilai ulangan,nilai ujian atau nilai raportnya tinggi dikatakan mempunyai prestasi belajar,Sebaliknya siswa yang nilai ulangan,nilai ujian atau nilai raportnya rendah mempunyai prestasi belajar yang rendah.

\section{Metode Penelitian}

Jenis penelitian ini adalah penelitian kuantitatif. Desain eksperimen yang digunakan adalah one group pretest-posttest design

\begin{tabular}{cccc}
\multicolumn{4}{c}{ Tabel 1.1. Desain Eksperimen } \\
\hline Sampel & Pretes & Perlakuan & Posttest \\
\hline 1 & $T_{1}$ & $\mathrm{X}$ & $T_{2}$ \\
& & & \\
\hline \multicolumn{4}{c}{ (Sugiyono, 2008:114) }
\end{tabular}

Penelitian ini dilaksanakan di kelas VIII SMP Negeri 20 Kupang, penelitian ini dilaksanakan pada semester ganjil tahun pelajaran 2018/2019. Populasi dalam penelitian ini yaitu seluuh siswa kelas VII SMPN 20 Kupang.Sampel penelitian ini adalah satu kelas yang diambil secara acak dengan menggunakan teknik simple random sampling.

Teknik pengumpulan data yang digunakan dalam penelitian ini berupa observasi dan tes. Observasi dilakukan oleh dua orang pengamat untuk mengetahui kondisi lingkungan belajar siswa, melihat aktivitas pembelajaran guru dan siswa khususnya mengenai model pembelajaran Tutor sebaya yang diterapkan. Tes dilaksanakan berbentuk pilihan ganda dengan jumlah soal 30. Tes ini digunakan untuk melihat seberapa jauh siswa mampu menggunakan pengetahuan yang telah dimiliki. 


\section{Hasil Penelitian dan Pembahasan}

\section{Hasil}

Skor capaian indikator pelaksanaan pembelajaran dengan menerapkan Model pembelajaran Tutor Sebaya terhadap prestasi belajar dapat dilihat pada tabel berikut:

Tabel 1.2 Capaian Indikator Pelaksanaan Pembelajaran

\begin{tabular}{|c|c|c|c|}
\hline & $\begin{array}{c}\text { Skor } \\
\text { Pengamat } \\
1\end{array}$ & $\begin{array}{c}\text { Skor } \\
\text { Pengamat } \\
2\end{array}$ & $\begin{array}{c}\text { Capaian } \\
\text { Indikator } \\
\text { (CI) }\end{array}$ \\
\hline $\begin{array}{c}\text { Pembelajaran } \\
01\end{array}$ & 114 & 111 & $\begin{array}{l}\frac{225}{256} \times 100 \\
=87,89\end{array}$ \\
\hline \multirow[t]{3}{*}{$\begin{array}{c}\text { Pembelajaran } \\
02\end{array}$} & 117 & 114 & $\begin{array}{l}\frac{231}{256} \times 100 \\
=90,23\end{array}$ \\
\hline & & & $87,89+90,23$ \\
\hline & \multicolumn{2}{|c|}{ RATA-RATA } & $\begin{array}{r}2 \\
=89,06\end{array}$ \\
\hline
\end{tabular}

Berdasarkan hasil analisis capaian indikator pembelajaran diatas, maka dapat disimpulkan bahwa kemampuan guru dalam mengelola pembelajaran dengan menerapkan Model pembelajaran Tutor Sebaya terhadap prestasi belajar pada siswa kelas VII SMPN 20 Kupang tergolong baik. Hasil analisis prestasi belajar siswa dapat dilihat pada gambar dibawah ini.

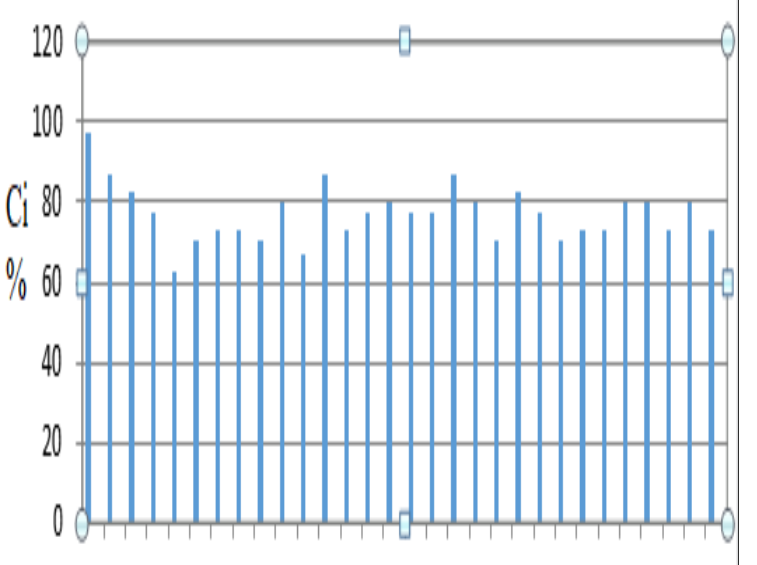

123456789101112131415161718192021222324252627282930 Butili' soal

Gambar 1. Capaian Indikator Butir Soal Posttest

\section{Pembahasan}

Hasil analisis pada SPSS diperoleh, nilai asymp.Sig.(2-Tailed) $=0,073>0,05$. Sedangkan nilai $D_{\text {hitung }}=0,153<0,242=$ $D_{\text {tabel }}$. Karena nilai $\mathrm{D}_{\text {hitung }}<\mathrm{D}_{\text {tabel }}$ maka $H_{o}$ diterima. Dengan demikian, disimpulkan bahwa data pretest berdistribusi normal.Hasil analisis pada SPSS diperoleh, nilai asymp.Sig.(2-Tailed) $=0,148>0,05$. Sedangkan nilai $D_{\text {hitung }}=0,138<0,242=$ $D_{\text {tabel }}$ Karena nilai $\mathrm{D}_{\text {hitung }}<\mathrm{D}_{\text {tabel }}$ maka $H_{o}$ diterima. Dengan demikian, disimpulkan bahwa data posttest berdistribusi normal.

Hasil analisis SPSS diperoleh nilai Sig. $(2-$ tailed $)=0,000$ dan $t_{\text {hitung }}=$ 16.417 dengan $d f=n-1$, diperoleh $d f=29$ dan taraf signifikan $\frac{\alpha}{2}=$ 0,025 diperoleh $t_{\text {tabel }}=2,045$ Karena nilai Sig. $(2-$ tailed $)=0,000<0,05 \quad$ dan $t_{\text {hitung }}=16.417>2,045=-t_{\text {tabel }}$ maka kriterian penerimaan hipotesis di atas maka, $H_{0}$ ditolak dan $H_{a}$ diterima sehingga disimpulkan bahwa ada pengaruh yang signifikan pada penerapan Model 
pembelajaran Tutor Sebaya terhadap prestasi belajar siswa kelas VII SMPN 20 kupang.

\section{Simpulan dan Saran}

\section{Simpulan}

Berdasarkan hasil penelitian dan pembahasan dapat disimpulkan bahwa:

Model pembelajaran Tutor sebaya pada siswa kelas 7 di SMPN 20 Kupang untuk pokok bahasan faktorisasi suku aljabar tahun ajaran 2018/2019 tergolong sangat baik.,Prestasi belajar matematika dengan model pembelajaran Tutor sebaya pada materi Faktorisasi suku aljabar siswa SMPN 20 Kupang kelas VII tahun ajaran 2018/2019 tercapai dengan predikat baik. dan Ada pengaruh yang signifikan model pembelajaran Tutor sebaya terhadap prestasi belajar matematika siswa kelas VII di SMP 20 Kupang untuk pokok bahasan Faktorisasi suku aljabar tahun ajaran 2018/2019.

\section{Saran}

Berdasarkan hasil penelitian yang di lakukan pada mata pelajaran matematika kelas VII pokok bahasan Faktorisasi suku aljabar tahun ajaran 2018/2019 maka peneliti memberikan rekomendasi sebagai berikut: Bagi guru dan calon guru matematika agar dapat menggunakan model pembelajaran Tutor sebaya sehingga siswa terlibat aktif dalam proses pembelajaran. Bagi siswa/ siswi, dengan diterapkannya model pembelajaran Tutor sebaya, diharapkan siswa harus bisa menigkatkan prestasi belajar, serta rasa percaya diri siswa dalam belajar, dan lebih bersemangat serta lebih aktif dalam mengikuti proses belajar mengajar. Bagi sekolah, sebagai masukan untuk menerapkan model pembelajaran Tutor sebaya untuk meningkatkan prestasi belajar matematika siswa.

\section{Daftar Pustaka}

Ahmad,Firdaus. (2009).Kemampuan Pemecahan Masalah Matematika. Diakses $23 \quad$ November 2018. http://madfirdaus.wordpress.com/(2009) /11/23/ kemampuan- pemecahan masalah matematika

Arikunto, S. (2008). Dasar-Dasar Evaluasi Pendidikan. Jakarta: Bumi Aksara.

Hamalik, Oemar. (2007). Perencanaan Pengajaran Berdasarkan Pendekatan Sistem. Jakarta: Bumi Aksara.

Slameto. (2003). Belajar dan Faktor-Faktor Yang Mempengaruhinya. Jakarta: PT.Rineka Cipta.

Sugiyono. (2010). Metode Penelitian Pendidikan. Bandung: Alfabeta. 